\title{
Congenital Humeroradial Synostosis: A Case Report
}

\author{
Sandeep Nema, MS Orth, G S Vyas, MS Orth, Ashish Sirsikar, MS Orth, Praveen K Bhoj, MBBS \\ Department of Orthopaedic Surgery, Melaka Manipal Medical College, Melaka, Malaysia
}

\begin{abstract}
We present here a unique case of humeroradial synostosis. These anomalies are due to longitudinal failure of differentiation. Approximately 150 cases of humeroradial synostosis have been reported worldwide, the majority of which are familial in nature or associated with syndromes. The case presented here involves an infant aged $1 \frac{1}{2}$ months, born with bilateral humeroradial synostosis without familial or syndromic association. To the best of our knowledge, no such case has been reported in Asia.
\end{abstract}

\section{INTRODUCTION}

McIntyre and Benson reported that developmental synostoses are classically divided on the basis of nature of

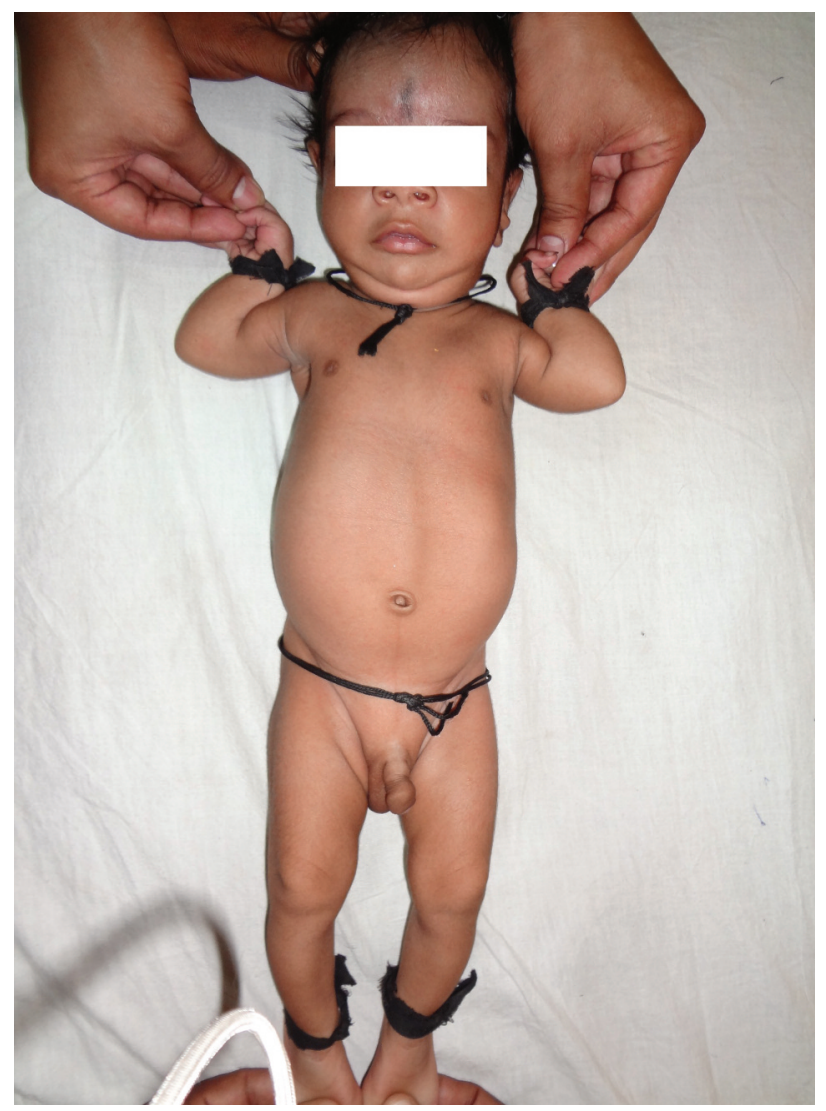

Fig. 1: Clinical photograph; Child keeping both his elbows in flexed position. bony ankylosis into humeroradial, humeroradioulnar and humeroulnar types ${ }^{1}$. They proposed an etiological classification for synostosis around the elbow in which bone hypoplasia is class I and joint maldevelopment is class II ${ }^{1}$. The present case is unique in that there was no familial or syndromic association. McIntyre and Benson identified only two sporadic reports in their study in humans ${ }^{1}$.

\section{CASE PRESENTATION}

The patient was a $1 \frac{1}{2}$ month infant whose parents complained that the child was keeping both his elbows in a flexed position since birth. He was their first child. Birth was at full term via normal vaginal delivery. There was no history of any maternal infection or exposure to teratogenic agents during pregnancy.

There was no family history of this condition in first degree relatives. Developmental milestones were normal for age. On clinical examination, the forearms were fixed at $110^{\circ}$ of flexion and there was neutral forearm rotation on both sides (Figure 1). No movement was possible at the elbow and radio-ulnar joints. The patient's hands were normal and there was no radial or ulnar hypoplasia bilaterally. There were no other skeletal abnormalities. Clinical examination revealed no abnormalities of cardiovascular system, central nervous

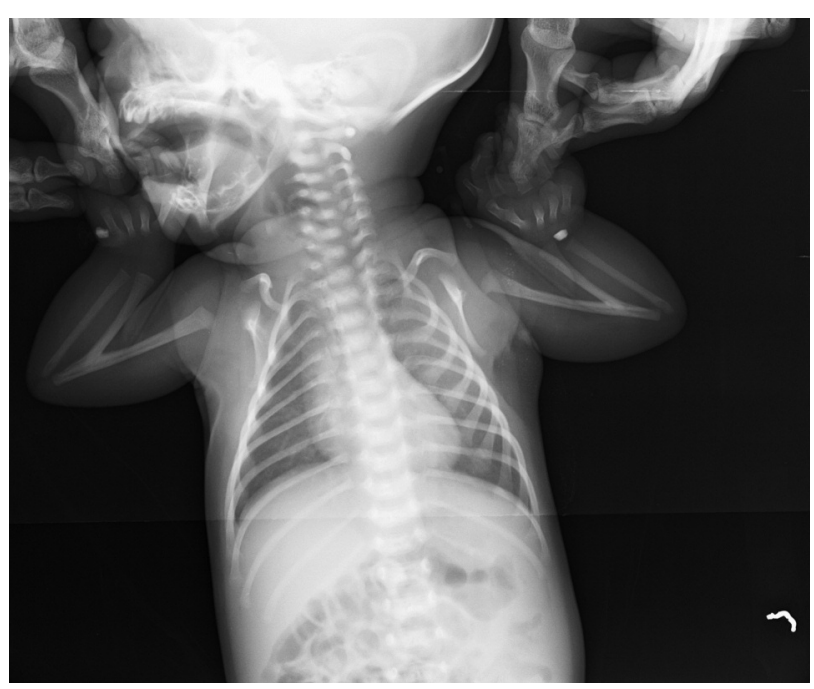

Fig. 2: Radiograph; Humeroradial synostosis.

Corresponding Author: Sandeep Nema, Department of Orthopaedics, Melaka Manipal Medical College, 75150, Melaka Email:drsandeepnema@gmail.com 
system, respiratory system, abdomen or genitalia. Ultrasonography and echocardiography did not reveal any other abnormalities. Synostosis of humeroradial joint was found on radiographic examination (Figure 2).

\section{DISCUSSION}

Humeroradial synostosis is due to the failure of longitudinal differentiation. Limb development is regulated by Hox genes (Hox A, B, C and D). The humerus, radius and ulna are contiguous with each other and are joined by common perichondrium at 5 weeks of gestation. Any insult during this period of rapid limb development can result in congenital anomalies of upper extremity ${ }^{1}$.

Most of these patients do well if the elbow is in a functional position provided that humeroradial synostosis is the only anomaly. According to various reports, these patients function well (i.e., earning livelihood) but they are dependent on others for certain personal needs ${ }^{2,3}$. There is a high reoccurrence rate of synostosis following surgical treatment, meaning that in most cases there does not seem to be a firm indication for surgical intervention ${ }^{2,4}$.

In the present case, the patient was too young to consider any operative procedure, but as he grows older we foresee limitations with respect to certain activities like writing. The child may face problems in toileting, cleaning his back, and in feeding. Any operative procedure performed in the future should address these needs by bringing at least one elbow to a functional position so that it can be repositioned to enable self-feeding and adequate toileting procedures. Our recommendation is one of careful observation of the patient's function; if necessary an osteotomy could be performed to obtain a more functional position of the elbows.

\section{REFERENCES}

1. McIntyre JD, Benson MK. An aetiological classification for developmental Synostoses at the elbow. J Pediatr Orthop B. 2002; 11(4): 313-9.

2. Jacobsen ST, Crawford AH. Humeroradial synostosis. J Pediatr Orthop. 1983; 3(1): 96-8.

3. Murphy, H. S. Hanson, C. G. congenital humeroradial synostosis. J Bone Joint Surg Am, 1945; 27(4): 712-3.

4. Fixsen JA. The shoulder and elbow in: Ed:Bensen, et al. Children's Orthopaedics and Fractures, 3rd ed. New York: Springer; 2009. 361 